\title{
Predictors of intramedullary lesion expansion rate on MR images of patients with subaxial spinal cord injury
}

\author{
Elizabeth Le, MD,, Bizhan Aarabi, MD, FRCSC,1,2 David S. Hersh, MD, ${ }^{1}$ \\ Kathirkamanthan Shanmuganathan, MD, ${ }^{2}$ Cara Diaz, CRNP, ${ }^{2}$ Jennifer Massetti, CRNP, ${ }^{2}$ \\ and Noori Akhtar-Danesh, $\mathrm{PhD}^{3}$
}

\begin{abstract}
'Department of Neurosurgery and ${ }^{2} \mathrm{R}$ Adams Cowley Shock Trauma Center, University of Maryland School of Medicine, Baltimore, Maryland; and ${ }^{3}$ School of Nursing and Department of Clinical Epidemiology and Biostatistics, McMaster University, Hamilton, Ontario, Canada
\end{abstract}

\begin{abstract}
OBJECT Studies of preclinical spinal cord injury $(\mathrm{SCl})$ in rodents indicate that expansion of intramedullary lesions (IMLS) seen on MR images may be amenable to neuroprotection. In patients with subaxial SCl and motor-complete American Spinal Injury Association (ASIA) Impairment Scale (AIS) Grade A or B, IML expansion has been shown to be approximately $900 \mu \mathrm{m} /$ hour. In this study, the authors investigated IML expansion in a cohort of patients with subaxial $\mathrm{SCl}$ and AIS Grade A, B, C, or D.
\end{abstract}

METHODS Seventy-eight patients who had at least 2 MRI scans within 6 days of SCI were enrolled. Data were analyzed by regression analysis.

RESULTS In this cohort, the mean age was 45.3 years (SD 18.3 years), 73 patients were injured in a motor vehicle crash, from a fall, or in sport activities, and $77 \%$ of them were men. The mean Injury Severity Score (ISS) was 26.7 (SD 16.7), and the AIS grade was $A$ in 23 patients, $B$ in 7, C in 7, and $D$ in 41. The mechanism of injury was distraction in 26 patients, compression in 22, disc/osteophyte complex in 29, and Chance fracture in 1. The mean time between injury onset and the first MRI scan (Interval 1) was 10 hours (SD 8.7 hours), and the mean time to the second MRI scan (Interval 2) was 60 hours (SD 29.6 hours). The mean IML lengths of the first and second MR images were $38.8 \mathrm{~mm}$ (SD $20.4 \mathrm{~mm}$ ) and $51 \mathrm{~mm}$ (SD $36.5 \mathrm{~mm}$ ), respectively. The mean time from the first to the second MRI scan (Interval 3) was 49.9 hours (SD 28.4 hours), and the difference in IML lengths was $12.6 \mathrm{~mm}$ (SD $20.7 \mathrm{~mm}$ ), reflecting an expansion rate of $366 \mu \mathrm{m} /$ hour (SD $710 \mu \mathrm{m} /$ hour). IML expansion in patients with AIS Grades A and B was $918 \mu \mathrm{m} /$ hour (SD $828 \mu \mathrm{m} / \mathrm{hour}$ ), and for those with AIS Grades C and D, it was $21 \mu \mathrm{m} /$ hour (SD $304 \mu \mathrm{m} /$ hour). Univariate analysis indicated that AIS Grade A or $B$ versus Grades $C$ or $D(p<0.0001)$, traction $(p=0.0005)$, injury morphology $(p<0.005)$, the surgical approach $(p=$ $0.009)$, vertebral artery injury ( $p=0.02)$, age $(p<0.05)$, ISS $(p<0.05)$, ASIA motor score $(p<0.05)$, and time to decompression $(p<0.05)$ were all predictors of lesion expansion. In multiple regression analysis, however, the sole determinant of IML expansion was AIS grade $(p<0.005)$.

CONCLUSIONS After traumatic subaxial cervical spine or spinal cord injury, patients with motor-complete injury (AIS Grade A or B) had a significantly higher rate of IML expansion than those with motor-incomplete injury (AIS Grade C or D). http://thejns.org/doi/abs/10.3171/2014.10.SPINE14576

KEY WORDS trauma; cervical spine; spinal cord injury; MRI

$\mathrm{D}$ ESPITE significant advances in methods of improving quality of life for people with spinal cord injury (SCI), full characterization of SCI and therapies to alter its course remain elusive. The importance of this condition is evidenced by the fact that every year, 12,000 people in the United States suffer an SCI, with an incidence of 40 per million. The worldwide population of people liv- ing with SCI is 2.5 million, resulting in immense personal burdens and societal costs. ${ }^{3,16,22,33,55,82}$ Although the means to reverse the initial damage to spinal cord tissues has yet to be discovered, halting the progression of the secondary injury at the molecular level seems promising. ${ }^{21,31,64,66,78,81}$

The results of preclinical studies in animal models indicate that $\mathrm{SCI}$ is not the result of a single static insult. Rather,

ABBREVIATIONS AIS = American Spinal Injury Association (ASIA) Impairment Scale; AMS = ASIA motor score; IML = intramedullary lesion; ISS = Injury Severity Score; $\mathrm{MABP}=$ mean arterial blood pressure; $\mathrm{MCC}=$ maximum canal compromise; $\mathrm{MSCC}=$ maximum spinal cord compression; $\mathrm{SCl}$ = spinal cord injury.

SUBMITTED June 9, 2014. ACCEPTED October 14, 2014.

INCLUDE WHEN CITING Published online March 6, 2015; DOI: 10.3171/2014.10.SPINE14576.

DISCLOSURE The authors report no conflict of interest concerning the materials or methods used in this study or the findings specified in this paper. 
it is a dynamic process defined by a distinctive cascade of molecular events after the initial trauma that creates a graded yet expansive intramedullary lesion (IML) that destroys spinal cord tissues, including endothelial cells, axons, myelin, and cell bodies. ${ }^{8,10,13,17,27,30,31,35,40,49,51,65,68}$ Unlike with motor-complete SCI, hematomyelia is absent in those with motor-incomplete SCI. These patients have axonal swelling and disruption in conjunction with minimal coagulative necrosis of the spinal cord parenchyma. ${ }^{1,2,24,26,46,53,59,75}$

As evident in experimental models of SCI, ${ }^{20,57,64} \mathrm{IML}$ expansion in humans has yet to be fully validated. ${ }^{2}$ At the microscopic level, histopathological studies have shown that IML expansion occurs primarily within the first 24 hours after trauma. ${ }^{42,45,48}$ At the clinical level, analyses of MR images acquired during the first 6 days of injury have shown that patients with motor-complete SCI have significantly longer IMLs than patients with motor-incomplete injury. ${ }^{1,2,34,54,61}$ An attempt to characterize the temporal evolution of these IMLs in motor-complete (American Spinal Injury Association [ASIA] impairment scale [AIS] Grades A and B) subaxial cervical SCI through examination of serial MR images revealed that the rate of rostrocaudal expansion of IML occurred at approximately $900 \mu \mathrm{m} /$ hour. $^{2}$ Because of the differing clinical courses and outcomes in motor-incomplete SCI (AIS Grades C and D), we sought to verify the rate of IML expansion in this patient population and compare it to the rate found in patients with motor-complete SCI. To our knowledge, no study has examined serial MR images of humans with motor-incomplete SCI.

Because the final IML size seems to correlate with motor function, the ability to halt IML expansion and ultimately reduce the extent of injury can potentially lead to decreased morbidity from SCI. In vivo rodent models of SCI indicate that IML expansion can be mitigated by chemotherapeutic agents. ${ }^{50,56,57,64}$ Thus, full characterization of IML expansion and identification of factors influencing its progression may help identify medical and surgical interventions that could alter the course of SCI and result in improved clinical outcomes. ${ }^{2,64}$ Our hypothesis was that in patients with subaxial cervical spine trauma and SCI, IML expansion remains constant across all AIS grades.

\section{Methods \\ Design}

This was a retrospective analysis of prospectively collected data.

\section{Primary Outcome}

We studied the IML expansion rate on MR images of patients with subaxial cervical SCI.

\section{Selection Criteria \\ Inclusion Criteria}

To be included in the study, patients had to have had the following: 1) age older than 15 years, 2) a blunt trauma resulting in subaxial cervical spine fracture dislocations and SCI, 3) diagnosis of an AIS Grade A, B, C, or D injury, and 4) good-quality postresuscitation and postoperative (up to 6 days postinjury) CT and MRI scans (with distinct IML borders) of the cervical spine available.

\section{Exclusion Criteria}

Excluded were patients who had the following: 1) a penetrating cervical spine and spinal cord injury, 2) AIS Grade E, 3) traumatic brain injury, 4) only 1 MRI scan or only CT myelograms, 5) a nontraumatic central cord syndrome, and 6) neurological worsening during the study period.

\section{Institutional Review Board Approval}

This study was approved by the institutional review board of the University of Maryland School of Medicine.

\section{Management Process}

\section{Emergency Medical, Prehospital, Trauma Center, and Critical} Care Management

Emergency medical, transportation, trauma resuscitation unit, and inpatient critical care management of patients with SCI was performed according to the guidelines of the Maryland Institute for Emergency Medical Services System and the Congress of Neurological Surgeons/American Association of Neurological Surgeons-approved guidelines for the management of cervical spine and spinal cord injury. ${ }^{4,9,41}$

\section{Clinical Evaluation and Imaging (CT and MRI) Studies}

After patients were resuscitated by volume expansion and blood pressure augmentation ${ }^{73}$ and considered stable, primary and secondary surveys were performed by medical and surgical staff of the trauma center. Each patient was examined by the neurosurgical staff (attending physician, senior resident, or nurse practitioners) to determine the ASIA motor score (AMS) and AIS grade ${ }^{76}$ Each patient was then transported to undergo CT scanning of the cervical spine and $\mathrm{CT}$ angiography. ${ }^{1,2} \mathrm{CT}$ was used to assign a mechanistic phylogeny and stage for each patient according to Allen et al. ${ }^{7}$ After the CT scan, each patient underwent MRI studies of the cervical spine. Patients with electromagnetically activated implants or those with metallic foreign bodies near the spinal column incompatible with MRI underwent $\mathrm{CT}$ myelography to rule out the need for spinal cord decompression. Subjects with an intrinsic spinal cord lesion and no spinal cord compression underwent preoperative MRI only; however, those who underwent surgery for spinal cord decompression routinely had at least 1 postoperative MRI scan to verify spinal cord decompression.

\section{Calculation of Maximum Canal Compromise, Maximum Spinal Cord Compression, and IML Expansion Rate}

We used T2-weighted images or STIR sequences to determine maximum canal compromise (MCC) and maximum spinal cord compression (MSCC), as originally reported by Fehlings et al. and validated in several independent investigations. ${ }^{28,29,38,39,54}$ The mean interval from the injury to the time of acquisition of the first MRI scan was 10 hours (SD 8.7 hours; range 3-67.2 hours); this period was called Interval 1 . The second MRI scan was per- 
formed a mean of 60 hours (SD 29.6 hours; range 15-134 hours) after trauma; this time period was called Interval 2 . The mean time between the first and second MRI studies was 49.9 hours (SD 28.4 hours; range 9-124 hours) and was called Interval 3. MRI after trauma was used to determine the following parameters: 1) the IML length at the end of Interval 1 (IML1, in millimeters ); 2) the sagittal diameter of the spinal canal at the site of skeletal injury (Di, in millimeters ); 3) the MCC at the site of injury (in percent); and 4) the MSCC at the site of injury (in percent). The MCC and MSCC were calculated as follows using previously validated formulas: ${ }^{29,39}$

$$
\mathrm{MCC}=[(\mathrm{Da}+\mathrm{Db}) / 2-\mathrm{Di}] /(\mathrm{Da}+\mathrm{Db}) / 2 \times 100,
$$

where Di is the subaxial cervical spine sagittal diameter at the level of injury, $\mathrm{Da}$ is the midsagittal diameter of the spinal canal 1 or 2 motion segments above the level of injury, and $\mathrm{Db}$ is the midsagittal diameter of the spinal canal 1 or 2 motion segments below the level of spinal injury. The MSCC was calculated according to the following formula:

$$
\operatorname{MSCC}=[(\mathrm{da}+\mathrm{db}) / 2-\mathrm{di}] /(\mathrm{da}+\mathrm{db}) / 2 \times 100,
$$

where da is the diameter of the spinal cord at a normal segment above the level of SCI, db is the diameter of the spinal cord at a segment below the level of SCI, and di is the diameter of the spinal cord at the level of SCI (Fig. 1).

The second MRI scans were used to measure the rostrocaudal IML length at the end of Interval 2 (IML2, in millimeters). The rate of IML expansion was calculated according to the following formula:

$$
\text { rate }=(\text { IML2 }- \text { IML1 }) /(\text { Interval } 2-\text { Interval } 1) .
$$

\section{Medical Management}

Each patient's postresuscitation mean arterial blood pressure (MABP) was kept at approximately $85 \mathrm{~mm} \mathrm{Hg}$ for 7 days, as recommended, unless not medically advised because of comorbidities or age..$^{14,52,73}$ Methylprednisolone for SCI was part of our medical management protocol from 2005 to $2010 .{ }^{44,63}$ Medical management was continued for each patient in the critical care or intermediate care facility until he or she was discharged to a rehabilitation center.

\section{Closed Reduction}

Patients with unilateral or bilateral facet dislocations (flexion distraction Stage 2 or 3) and those with significant compressive flexion injuries (teardrop fractures) underwent attempted closed reduction as a preliminary step before definitive spinal cord decompression. Closed reduction was not attempted for facet subluxations, Chance fractures, or extension injuries. In the majority of patients, closed reduction was performed after the admission CT and MRI studies. It is our practice to apply 5-7 lbs of traction per motion segment (counting from C-1) to complete closed reduction within a maximum interval of 1-2 hours.

\section{Surgery}

The surgical procedure prescribed for each individual

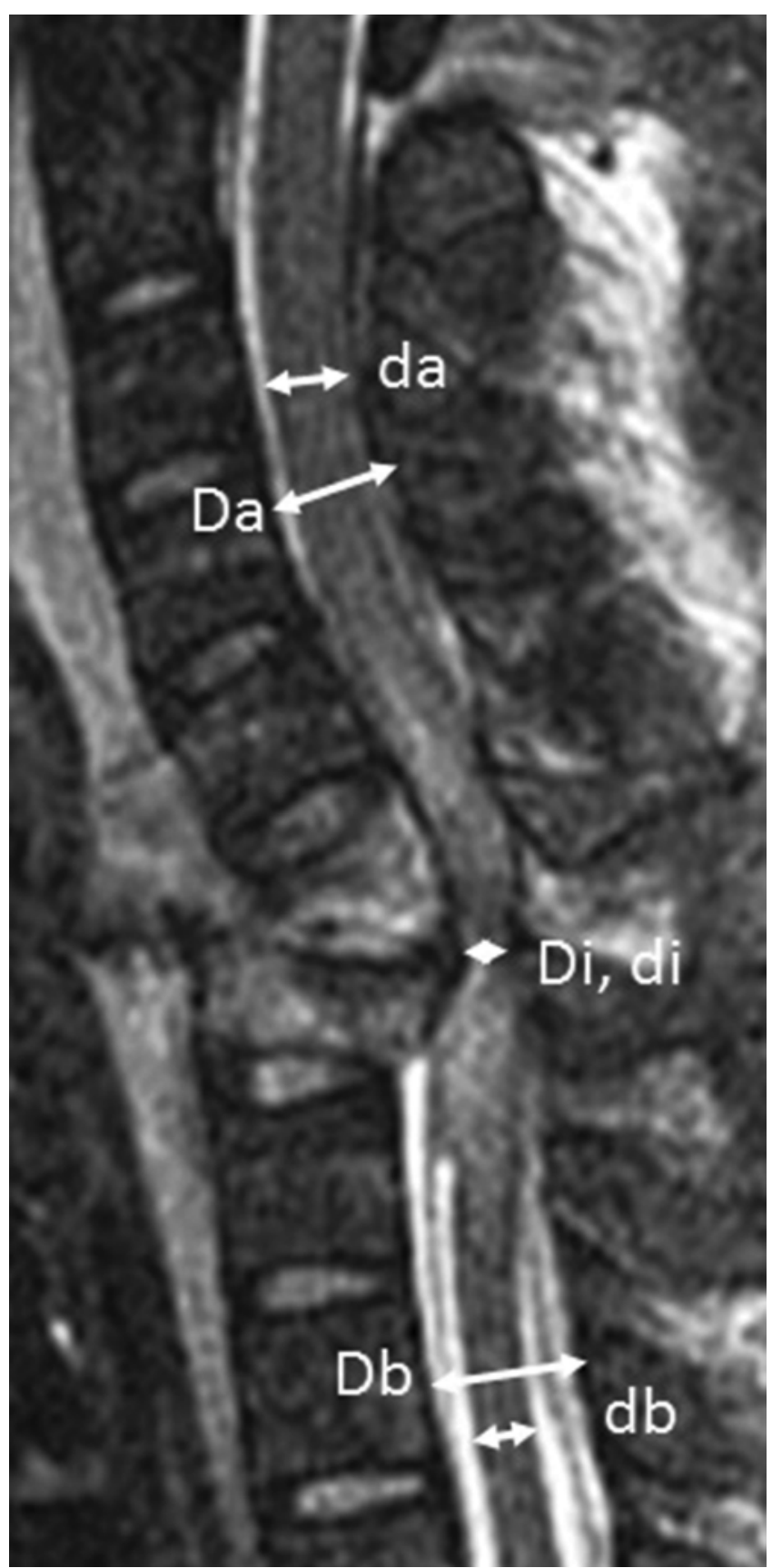

FIG. 1. Midsagittal reformatted STIR image obtained 8.5 hours after trauma in a 27-year-old man who was involved in an automobile accident and sustained a C-6 teardrop fracture that resulted in quadriplegia. On admission, his AMS was 27 and his AIS grade was A. He underwent circumferential realignment, decompression, and internal fixation 20 hours after the trauma. The image indicates the $\mathrm{Da}, \mathrm{Di}, \mathrm{Db}$, da, di, and $\mathrm{db}$, parameters that were used to calculate the MCC and MSCC. The patient continued to have an AMS of 28 and AIS grade of A 11 months after the trauma. See Calculation of Maximum Canal Compromise, Maximum Spinal Cord Compression, and IML expansion Rate for the full explanation.

patient was determined by the injury severity, morphology according to Allen's classification, and the presence of spinal instability. ${ }^{7,72}$ Overall, each patient with a facet dislocation, a teardrop fracture, or a vertical distraction 
TABLE 1. Characteristics of 78 patients with motor-complete and motor-incomplete subaxial SCls

\begin{tabular}{|c|c|c|c|}
\hline Variable & All Patients & Patients w/ Motor-Complete SCI & Patients w/ Motor-Incomplete SCI \\
\hline No. of patients & 78 & 30 & 48 \\
\hline Male sex (no. [\%]) & $60(77)$ & $26(86.7)$ & $34(71)$ \\
\hline Age (mean [SD]) (yrs) & $45.3(18.3)$ & $33.1(12.8)$ & $52.8(17.1)$ \\
\hline \multicolumn{4}{|l|}{ Mechanism (no. [\%]) } \\
\hline Motor vehicle crash & $30(38.5)$ & $17(56.7)$ & $13(27)$ \\
\hline Fall & $26(33.3)$ & $5(16.7)$ & $21(43.8)$ \\
\hline Sport & $17(21.8)$ & $6(20)$ & $11(23)$ \\
\hline Other & $5(6.4)$ & $2(6.7)$ & $3(6.3)$ \\
\hline Admitting ASIA motor score (mean [SD]) & $53.6(35.2)$ & $14.4(11.5)$ & $78.1(18.8)$ \\
\hline \multicolumn{4}{|l|}{ AIS grade (no. [\%]) } \\
\hline A & $23(29.5)$ & $23(76.7)$ & $0(0.0)$ \\
\hline $\mathrm{B}$ & $7(9)$ & $7(23.3)$ & $0(0.0)$ \\
\hline C & $7(9)$ & $0(0.0)$ & $7(14.6)$ \\
\hline $\mathrm{D}$ & $41(52.6)$ & $0(0.0)$ & $41(85.4)$ \\
\hline \multicolumn{4}{|l|}{ Injury severity } \\
\hline ISS (mean [SD]) & $26.7(16.7)$ & $41.5(17.7)$ & $17.3(5.4)$ \\
\hline \multicolumn{4}{|l|}{ Morphology of injury (no. [\%]) } \\
\hline Distraction & $26(33.3)$ & $16(53.3)$ & $10(20.8)$ \\
\hline Compression & $22(28.2)$ & $12(40.0)$ & $10(20.8)$ \\
\hline Disc/osteophyte complex & $29(37.2)$ & $2(6.7)$ & $27(56.3)$ \\
\hline Other & $1(1.3)$ & $0(0)$ & $1(2.1)$ \\
\hline Subaxial sagittal diameter (mean [SD]) $\left(\mathrm{mm}^{3}\right)$ & $6.8(2)$ & $7.1(2.4)$ & $6.7(1.7)$ \\
\hline MCC (mean [SD]) (\%) & $42.2(14)$ & $45.9(16.4)$ & $39.9(12.3)$ \\
\hline MSCC (mean [SD]) (\%) & $7.5(22)$ & $5.7(30.6)$ & $8.6(15.1)$ \\
\hline \multicolumn{4}{|l|}{ IML length (mean [SD]) (mm) } \\
\hline During Interval 1 & $38.8(20.4)$ & $59.0(15.3)$ & $26.3(10.8)$ \\
\hline During Interval 2 & $51(36.5)$ & $87.4(33.5)$ & $28.2(11.3)$ \\
\hline IML expansion rate (mean [SD]) (mm/hr) & $366(712)$ & $920(820)$ & $20(340)$ \\
\hline \multicolumn{4}{|l|}{ Management (no. [\%]) } \\
\hline \multicolumn{4}{|l|}{ Surgical approach } \\
\hline Anterior & $24(30.7)$ & $4(13.3)$ & $20(41.7)$ \\
\hline Posterior & $10(12.8)$ & $1(3.3)$ & $9(18.8)$ \\
\hline Circumferential & $44(56.5)$ & $25(83.3)$ & $19(39.6)$ \\
\hline Steroids & $47(60)$ & $25(83.3)$ & $22(45.8)$ \\
\hline \multicolumn{4}{|l|}{ Outcome } \\
\hline AMS at follow-up (mean [SD]) & $69.1(37)$ & $22(17.5)$ & $94.6(8.5)$ \\
\hline \multicolumn{4}{|l|}{ AIS grade at follow-up* (no. [\%]) } \\
\hline A & $22(28.2)$ & $22(81.5)$ & $0(0)$ \\
\hline $\mathrm{B}$ & $5(6.5)$ & $5(18.5)$ & $0(0.0)$ \\
\hline C & $2(2.5)$ & $0(0.0)$ & $2(3.9)$ \\
\hline $\mathrm{D}$ & $40(51.3)$ & $0(0)$ & $40(78.4)$ \\
\hline$E$ & $9(11.5)$ & $0(0)$ & $9(17.7)$ \\
\hline Mean follow-up (mos) & 21.4 & 15 & 31 \\
\hline
\end{tabular}

* Because of their improved conditions, some patients' grades were different at follow-up (motor-complete SCI, $n=27$; motor-incomplete SCl, $n=51$ ).

injury underwent surgery via a circumferential approach to ensure that the construct being placed did not fail over time. Any patient with an extension-distraction injury associated with disc/osteophyte complexes or spinal stenosis underwent decompression and fusion via either an anterior or posterior approach alone, because there were usually no associated facet subluxations or dislocations. ${ }^{25,30,50,79}$

\section{Follow-Up}

After acute care and discharge, each patient was fol- 
lowed up to record the full degree of his or her neurosurgical recovery. The majority of the patients were followed up at institutions affiliated with the University of Maryland School of Medicine.

\section{Safeguard for Bias}

Selection bias was prevented by controlling for the following variables: MRI and surgical intervention intervals, age, sex, mechanism of injury, Injury Severity Score (ISS), admission and follow-up AMS and AIS grade, Allen et al. morphology phylogenies, vertebral artery injury, MCC, MSCC, closed reduction, steroid protocol, and surgical technique. $^{74}$

\section{Statistical Analysis}

We report descriptive statistics as the mean and SD for continuous variables and frequencies and proportions for categorical variables. First, a univariate analysis was conducted to assess the association between any independent variable and the IML expansion rate. Because of the small sample sizes and nonnormal distribution of the outcome variable, a Mann-Whitney U-test or Kruskal-Wallis test was used to examine the association between the IML expansion rate and the categorical independent variables. In addition, a Spearman correlation was used to assess the correlation between the IML expansion rate and the other continuous variables. Finally, we performed a multiple regression analysis to assess the relationships between the IML expansion rate and the independent variables that were significant in the univariate analysis. We used the statistical program Stata SE/12.1 (release 12; Stata Corp LP) for analysis.

\section{Results}

From January 2005 to December 2012, 984 patients were admitted to the University of Maryland R Adams Cowley Shock Trauma Center with traumatic subaxial cervical SCI, of whom 78 consecutive subjects were eligible for our study. Table 1 lists the baseline characteristics of these patients along with the injury classifications and management variables. Under the mechanisms of injury in Table 1, the "other" category includes assault and battery in 3 patients and fall of heavy object on the head in 2 patients. On the basis of their AIS grade, we categorized the patients as having motor-complete SCI or motor-incomplete SCI.

\section{Volume Expansion and Blood Pressure Augmentation}

Of our 78 patients, 73 had detailed vital signs recorded for the entirety of the period between arrival and the second MRI scan. Of these 73 patients, $22(30 \%)$ had at least 1 episode of an MABP of $<60 \mathrm{~mm} \mathrm{Hg}$ for at least $15 \mathrm{~min}$ utes. Fifty-one patients $(70 \%)$ had a stable MABP $(\geq 60$ $\mathrm{mm} \mathrm{Hg}$ ) for the time interval of interest. The average IML expansion was $340 \mu \mathrm{m} /$ hour (SD $710 \mu \mathrm{m} /$ hour) in patients with evidence of assumed ischemic episodes and $410 \mu \mathrm{m} /$ hour (SD $737 \mu \mathrm{m} /$ hour) in patients without evidence of ischemic episodes. This difference was not statistically significant $(\mathrm{p}=0.41)$.

\section{CT Scanning and CT Angiography}

Fourteen (18\%) of 78 patients did not undergo vascular studies. Of the remaining 64 patients, 19 (30\%) showed evidence of vertebral artery injury. Vertebral artery injury was on the left side in 7 , on the right side in 6 , and bilateral in 6 patients. Injury was Grade IV in 14, Grade III in 1 , Grade II in 2, and Grade I in 2 patients. The average IML expansion rate was $560 \mu \mathrm{m} /$ hour (SD $802 \mu \mathrm{m} /$ hour) in patients with vertebral artery injury and $390 \mu \mathrm{m} /$ hour (SD $743 \mu \mathrm{m} /$ hour) in patients without vertebral artery injury. Univariate statistical analysis indicated that this difference was significant $(\mathrm{p}=0.02)$; however, this difference lost its statistical value in multivariate regression analysis.

\section{MRI Studies}

In this investigation, 2 patients underwent CT myelography and 49 patients had an intrinsic spinal cord lesion without spinal cord compression. These patients did not undergo postoperative MRI studies and were excluded from the study. When the IML expansion rate was plotted against the timing of the first MRI acquisition, it was evident that the rate of expansion was faster closer to the time of trauma. The exact time of onset of IML expansion could not be determined from our retrospective data (Fig. 2).

\section{Steroid Protocol}

Of the 78 patients in our study, $31 \mathrm{did}$ not receive the steroid protocol, whereas 47 did $(30 \mathrm{mg} / \mathrm{kg} / \mathrm{hour}$ for 15 minutes and $5.4 \mathrm{mg} / \mathrm{kg} /$ hour for 24 hours). ${ }^{15}$ The average rate of IML expansion was $300 \mu \mathrm{m} /$ hour in patients treated with steroids and $409 \mu \mathrm{m} /$ hour in patients not treated with steroids. This difference did not achieve statistical significance $(\mathrm{p}=0.198)$.

\section{Closed Reduction}

Of our 78 patients, traction was not applicable in the 29 patients with SCI because of extension injuries with disc/ osteophyte complexes or in the 1 patient with a Chance fracture. Of the 26 patients with distraction injuries, 14 underwent closed reduction, which was successful in 8 patients. Of the 22 patients with compression fractures,

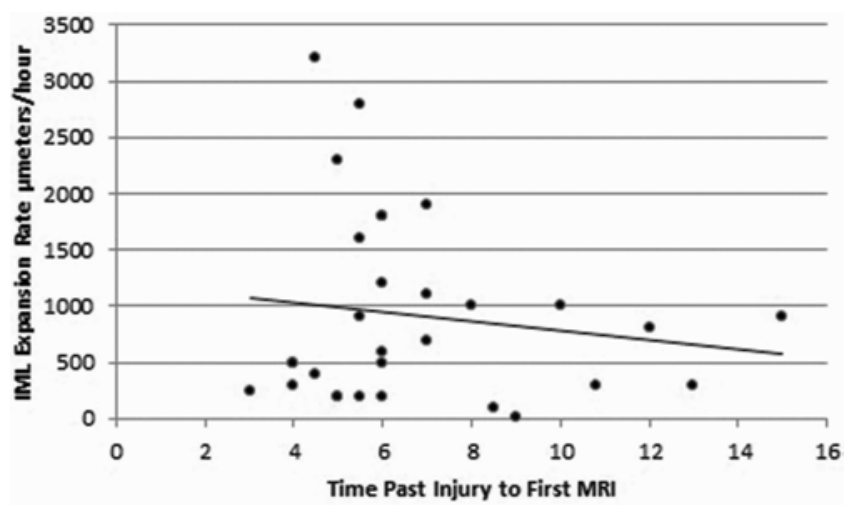

FIG. 2. Scatter plot demonstrating the relationship between the IML expansion rate and the time past injury to the first MRI scan (Interval 1). The expansion rate increases as the MR image acquisition approaches the time of trauma. 


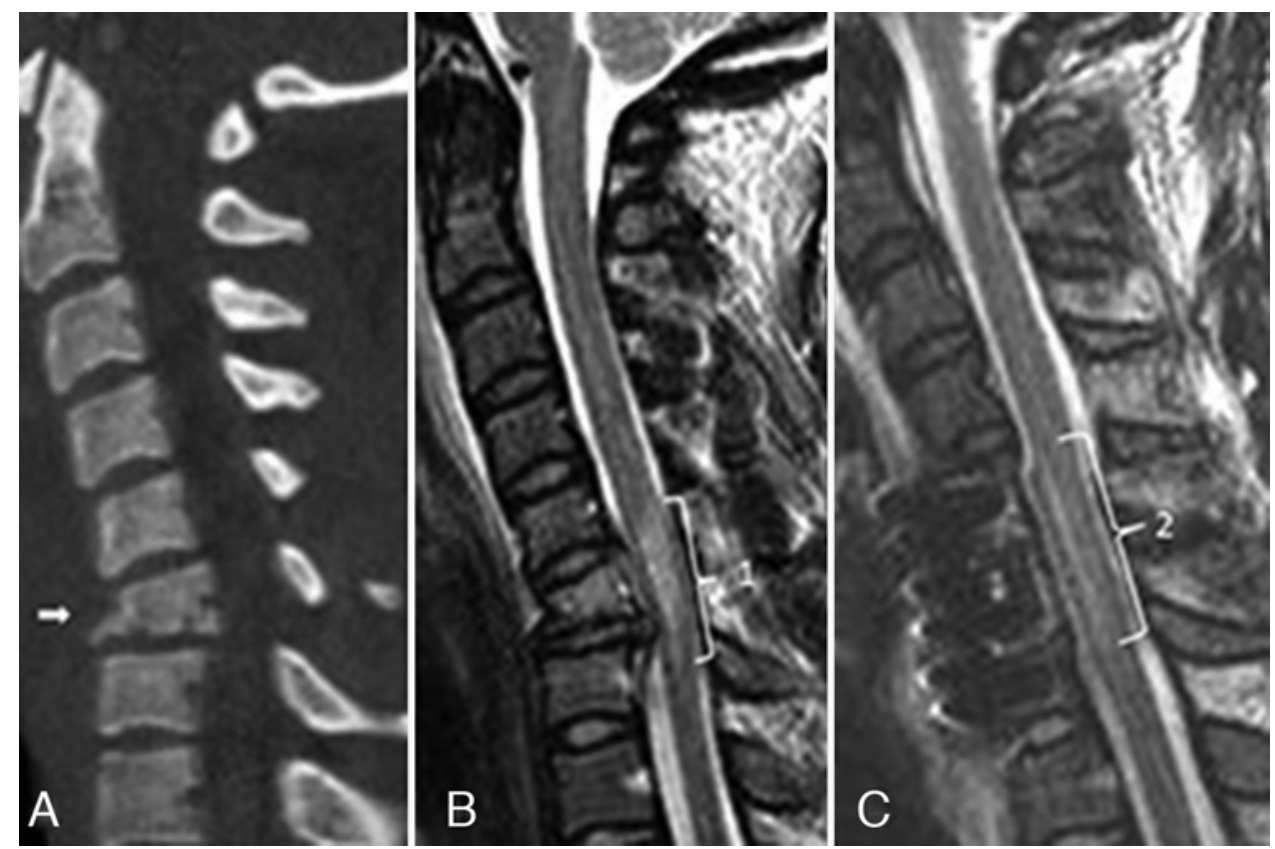

FIG. 3. Midsagittal reformatted CT and MR images of the cervical spine of a 20 -year-old woman admitted to the trauma resuscitation unit after an automobile accident with an AMS of 89 (AIS Grade D). Forty-two months after decompression and circumferential internal fixation, her AMS was 99 and her AIS grade was D. A: Teardrop compression fracture of C-6 (white arrow). B: A lesion $32 \mathrm{~mm}$ long with high signal intensity 14.4 hours after the trauma (bracket 1). C: At 64.8 hours after the injury and after decompression, realignment, and internal fixation, her MR image showed a high-intensity signal that was $35.9 \mathrm{~mm}$ long (bracket 2). The IML expansion rate in this patient was $80 \mu \mathrm{m} /$ hour.

3 underwent closed reduction, all of which were successful. The average IML expansion rate was $880 \mu \mathrm{m} /$ hour (SD $900 \mu \mathrm{m} /$ hour) in patients who had traction and 220 $\mu \mathrm{m} /$ hour (SD $580 \mu \mathrm{m} /$ hour) in patients who did not have traction. Univariate statistical analysis indicated that this difference was significant $(\mathrm{p}=0.0005)$. The significance, however, was lost in multivariate regression analysis.

\section{Surgical Decompression}

Of our 78 patients, the exact time interval between the injury and surgery was unknown for 6 patients. In the remaining 72 patients, 45 (62.5\%) underwent surgical intervention less than 24 hours after the trauma, and 27 (37.5\%) underwent surgical intervention 24 hours or more after injury. The mean IML rates of expansion in the first and second groups were $500 \mu \mathrm{m} /$ hour and $190 \mu \mathrm{m} /$ hour, respectively. Although this difference seems considerable ( $\mathrm{p}$ $<0.05$, univariate analysis), in the multivariate regression analysis, the interval between injury and surgery did not have a statistically significant effect on the rate of lesion expansion.

In this study, anterior, posterior, and circumferential surgical approaches were used in 24,10 , and 44 patients, respectively. The mean IML expansion rates were 152 $\mu \mathrm{m} /$ hour (SD $345 \mu \mathrm{m} /$ hour) in patients who underwent either the anterior or posterior surgical approach and 532 $\mu \mathrm{m} /$ hour (SD $867 \mu \mathrm{m} /$ hour) in those who underwent the circumferential surgical approach. Univariate statistical analysis indicated that this difference was significant $(\mathrm{p}=$ 0.009); however, the significance was lost in the multivariate regression statistical analysis.

\section{AlS Grade}

The mean rostrocaudal IML lengths seen on the first and second MRI scans were $38.8 \mathrm{~mm}$ (SD $20.4 \mathrm{~mm}$ ) and $51 \mathrm{~mm}$ (SD $36.5 \mathrm{~mm}$ ), resulting in a difference in lesion length of $12.6 \mathrm{~mm}$ (SD $20.7 \mathrm{~mm}$ ) between the 2 scans. As a result, the mean IML expansion rate was found to be 366 $\mu \mathrm{m} /$ hour (SD $710 \mu \mathrm{m} /$ hour) for the entire cohort. When lesion expansion was analyzed separately for patients with motor-complete (AIS Grade A or B) and motor-incomplete (AIS Grade C or D) SCI, the rate was significantly different. The mean rate of lesion expansion in patients with AIS Grade A or B was found to be $918 \mu \mathrm{m} /$ hour (SD 828 $\mu \mathrm{m} /$ hour), whereas that in those with AIS Grade C or D was much lower $(21 \mu \mathrm{m} /$ hour [SD $304 \mu \mathrm{m} /$ hour] $)$. In comparison with the rapid rate of expansion seen in patients with motor-complete SCI, the rate in patients with motorincomplete SCI was nearly static and even showed regression in some patients.

\section{Case 1}

A 20 -year-old woman sustained injury in a motor vehicle crash and was admitted to our center with an AMS of 89 and AIS grade of D. CT scanning revealed a C-6 compressive flexion Stage 3 injury. The IML length on the admission MR images, acquired 14.4 hours after the accident, was $32.0 \mathrm{~mm}$, and the IML length in the second MR images, acquired 64.8 hours after injury, was $35.9 \mathrm{~mm}$. The rate of IML expansion was $80 \mu \mathrm{m} /$ hour. Forty-two months after the trauma, her AMS was 99 and AIS grade was D (Fig. 3). 

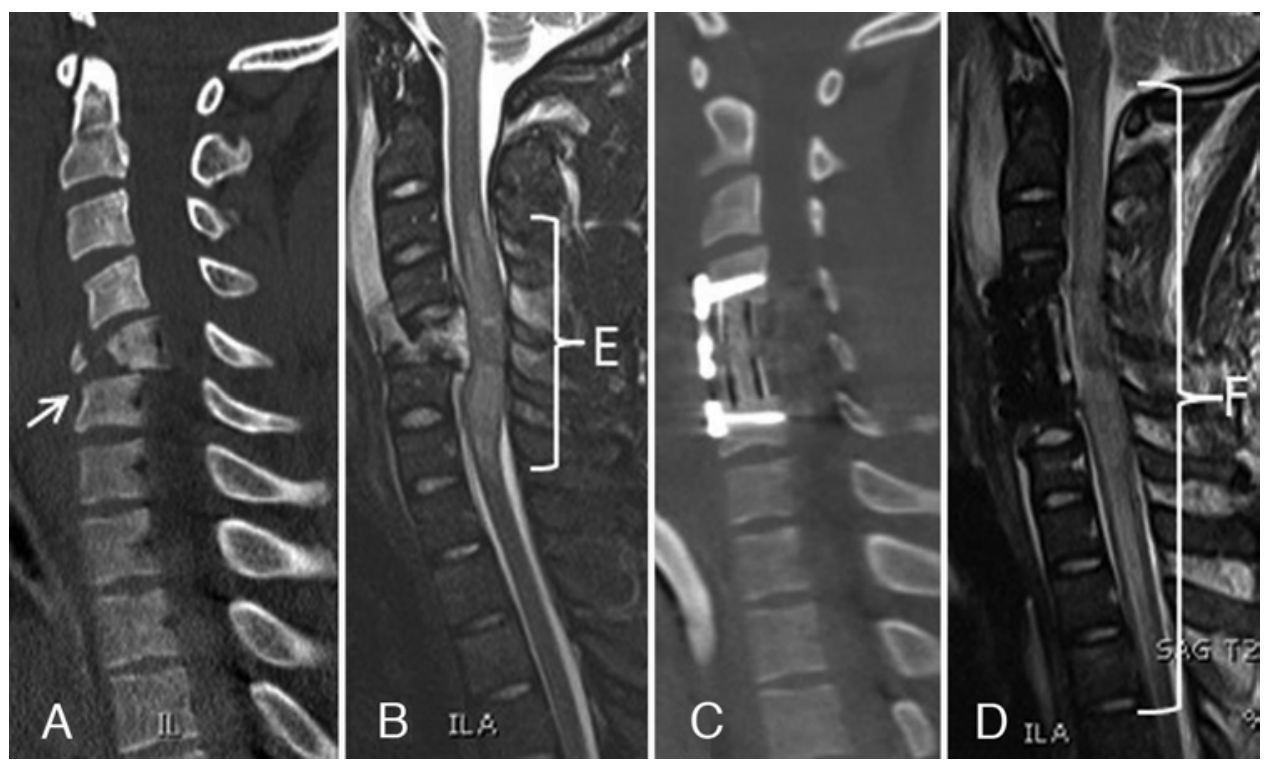

FIG. 4. Midsagittal preoperative ( $A$ and $B$ ) and postoperative ( $C$ and $D) C T$ and $M R$ images of a 25 -year-old man who sustained a traumatic C-5 compression fracture. At the time of admission, his AMS was 12 and his AIS grade was A. Ten months after injury, he remained quadriplegic. Shown are a C-5 teardrop fracture (A) (white arrow), a preoperative MR image 4.5 hours after injury with an intramedullary high-intensity signal measuring $76.2 \mathrm{~mm}$ in length (B) (bracket E), a postoperative CT image (C), and a postoperative MR image 44 hours after injury demonstrating an IML measuring $259 \mathrm{~mm}$ in length (D) (bracket F). The IML expansion rate was $3200 \mu \mathrm{m} / \mathrm{hour}$.

\section{Case 2}

While trimming a tree branch, a 25-year-old man sustained a C-5 teardrop (compressive flexion Allen Stage 4) ${ }^{7}$ fracture and became quadriplegic. His admission AMS was 12 and AIS grade was A. The IML length on the admission MR images, acquired 4.5 hours after injury, was $76.2 \mathrm{~mm}$, and the IML length on the postoperative MR images acquired 44 hours after admission was $205.9 \mathrm{~mm}$. The rate of expansion was $3200 \mu \mathrm{m} /$ hour (Fig. 4).

\section{Statistical Findings}

Univariate analysis of 9 prognostic indicators revealed that age ( $p=0.05 ;$ Fig. 5), ISS $(p=0.05)$, admission AMS $(p=0.05$; Fig. 6$)$, time between injury and surgery $(p=$ 0.05 ; Fig. 7), injury morphology $(\mathrm{p}=0.005$; Fig. 8$)$, and SCI severity (AIS Grade A or B vs AIS Grade C or D, $p$ $<0.0001$; Fig. 9) affected the IML expansion rate. When analyzed by regression analysis, however, only AIS grade significantly influenced the IML expansion rate $(\mathrm{p}=$ 0.005) (Table 2).

\section{Discussion}

Analyses of the data from this investigation indicate that AIS grade significantly influences the lesion expansion rate after traumatic SCI.

Light and electron microscopic studies in animal models of traumatic SCI by Dohrmann et al. and Wagner et al..$^{23,24,75}$ indicated that within 5 minutes of a compressive and contusive SCI, congestion of venules in the capillaryrich central gray matter was followed by a break in endothelial integrity and extravasation of red blood cells, producing hematomyelia. Microangiographic studies by
Fairholm and Turnbull ${ }^{26}$ revealed a fluffy extravasation of contrast material in the central part of the spinal cord within 10 minutes. $5,6,23,24,26,69,70,75$ From 4 to 7 days after SCI, capillary perfusion in the central gray matter was disrupted permanently and replaced by myelomalacia and coagulative necrosis. ${ }^{25}$ Numerous preclinical studies have indicated that immediately after SCI, the disruption of endothelial cells, axons, and the cytoskeleton, in association with molecular cascades and ionic imbalances, results in cytotoxic and vasogenic spinal cord edema, collectively labeled "secondary injury." 11-13,17-19,26,35,36,43,62, 65,67,68

The results of combined MRI and necropsy investigations by Quencer et al., ${ }^{59}$ Jimenez et al., ${ }^{46}$ and Martin et al. ${ }^{53}$ of patients who died within a few days after acute traumatic central cord syndrome indicated that axonal swelling and disruption in association with minimal co-

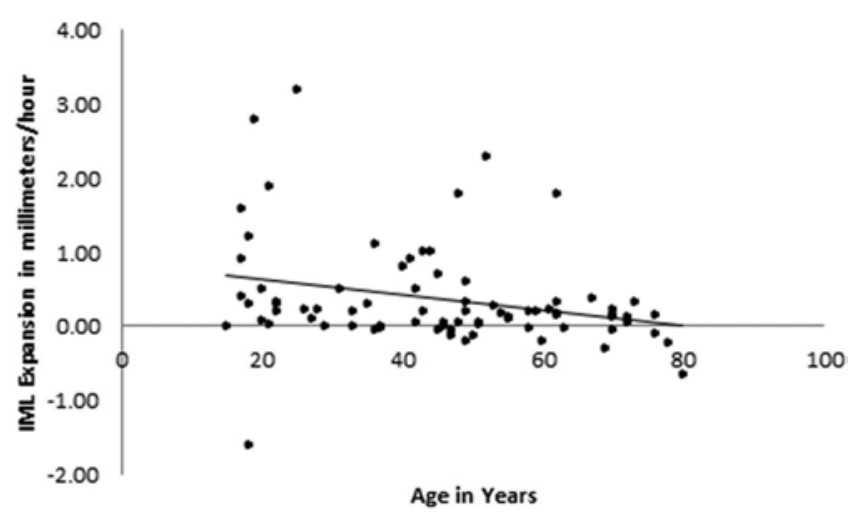

FIG. 5. Scatter plot illustrating a progressive decline in IML expansion with increased patient age. 


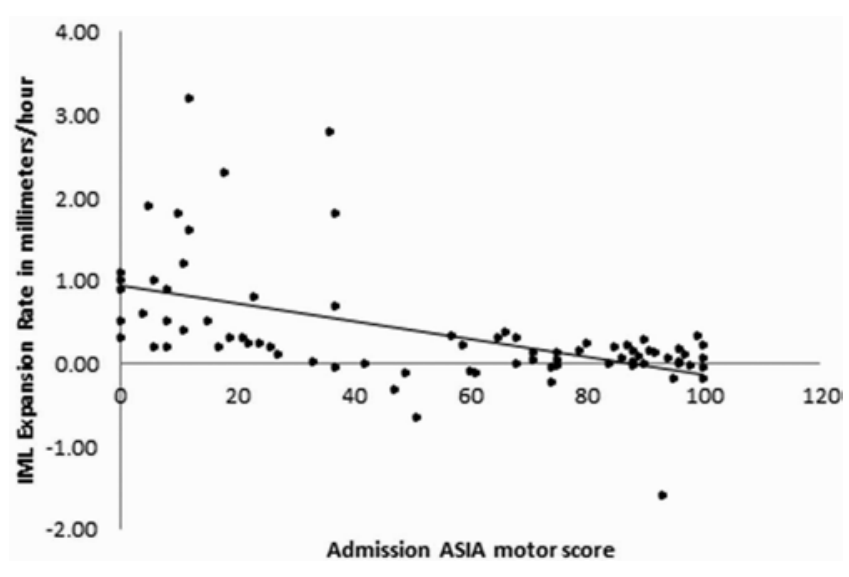

FIG. 6. Scatter plot demonstrating the relationship between the IML expansion rate and AMS at admission. Lower AMSs tended to have faster IML expansion rates.

agulative necrosis of gray matter are visualized as a highintensity signal IML on T2-weighted MR images. These patients with partial SCI did not show hematomyelia in histological sections. Similarly, none of the patients with AIS Grade C or D in our investigation had hematomyelia on MRI. In contrast, studies of patients with complete subaxial SCI since the 1990s have clearly depicted associated intramedullary hematomyelia and swelling, as seen in our investigation in the patients with motor-complete SCI. ${ }^{1,2,34,54,60,61}$ Hematomyelia was often seen in complete SCI in association with an IML length that exceeded a single motion segment in the studies of Flanders et al., ${ }^{34}$ Schaefer et al., ${ }^{61}$ and Miyanji et al. ${ }^{54}$ who demonstrated a relationship between injury severity and IML length. ${ }^{2}$ In 2007, Miyanji et al. ${ }^{54}$ reported on the IML length in patients with complete versus those with incomplete SCI. In their study, IML length was approximately $20 \mathrm{~mm}$ in incomplete injuries and reached up to $40 \mathrm{~mm}$ in complete injuries. Further expansion of this concept was seen in 2012, when Aarabi et al. ${ }^{2}$ reported that IML length on MR images is a dynamic phenomenon with an expansion rate of $900 \mu \mathrm{m} /$ hour. In the present investigation, applying a regression model to control for age, ISS, inpatient hypotensive episodes, injury morphology, vertebral artery injuries,

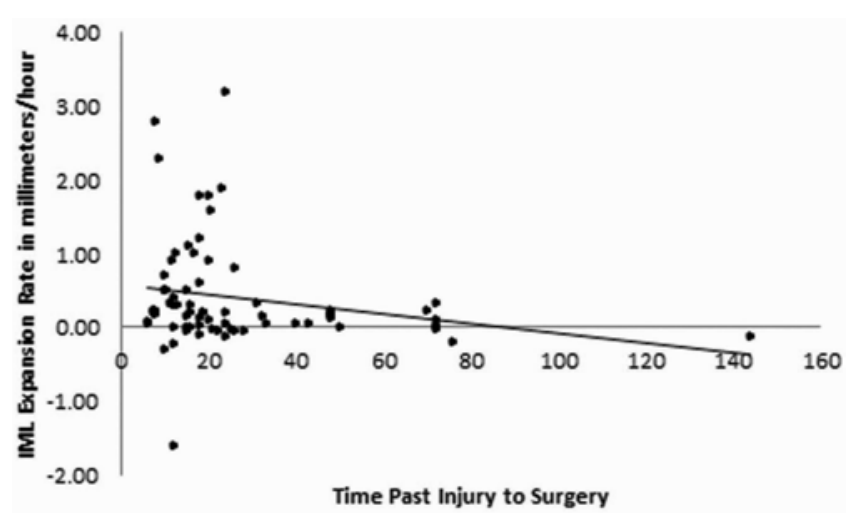

FIG. 7. Scatter plot depicting the relationship between time to surgery and the IML expansion rate.

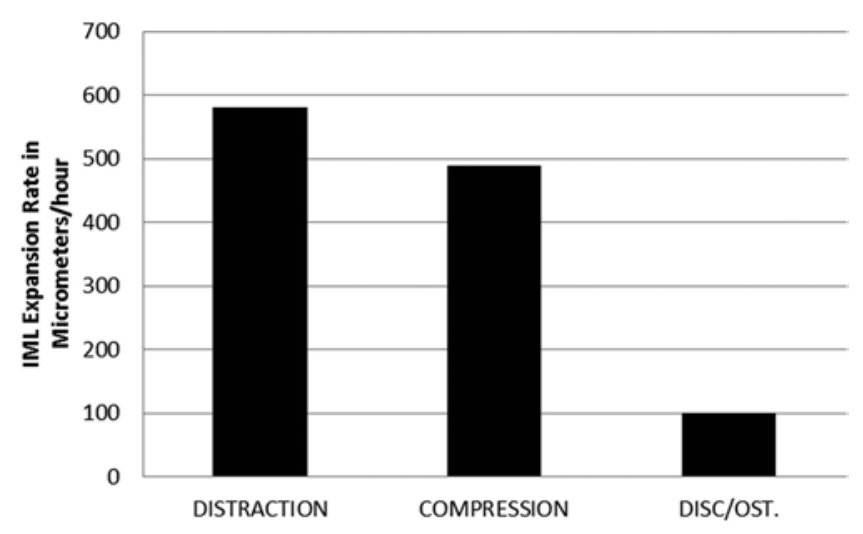

FIG. 8. Histogram showing the relationship between injury morphology and the IML expansion rate. DISC/OST = disc/osteophyte complex.

performance of closed reduction, steroid protocol, operative technique, and the timing of decompression, the expansive character of the IML in patients with motor-complete SCI was validated to be close to $920 \mu \mathrm{m} /$ hour. To our surprise, however, in patients with motor-incomplete SCI (AIS Grades C and D), the IML length-expansion rate was almost static ( $20 \mu \mathrm{m} /$ hour; Fig. 9$)$ without the aggressive expansive character observed in patients with motorcomplete SCI (AIS A and B).

In vivo preclinical MRI studies by Nout et al. ${ }^{57}$ Chou et al., ${ }^{20}$ and Simard et al. ${ }^{64}$ indicated that not only is an IML clearly demonstrated in experimental animals, but expansion of the lesion may also respond to neuroprotection. ${ }^{37}$ In those investigations, hypertonic saline, $S$-nitrosoglutathione, and glibenclamide slowed the progression of the molecular cascades seen in secondary injury, thereby shortening the final IML length. Our present investigation supports the notion that secondary injury may be much more intense in patients with motor-complete SCI than in those with incomplete SCI and may require the initiation of more aggressive neuroprotection at an earlier time to attenuate IML expansion.

Considering the nearly static nature of the IML in motorincomplete subaxial cervical SCI, one possible implication of this study is the potential difference between patients with motor-incomplete and those with motor-complete

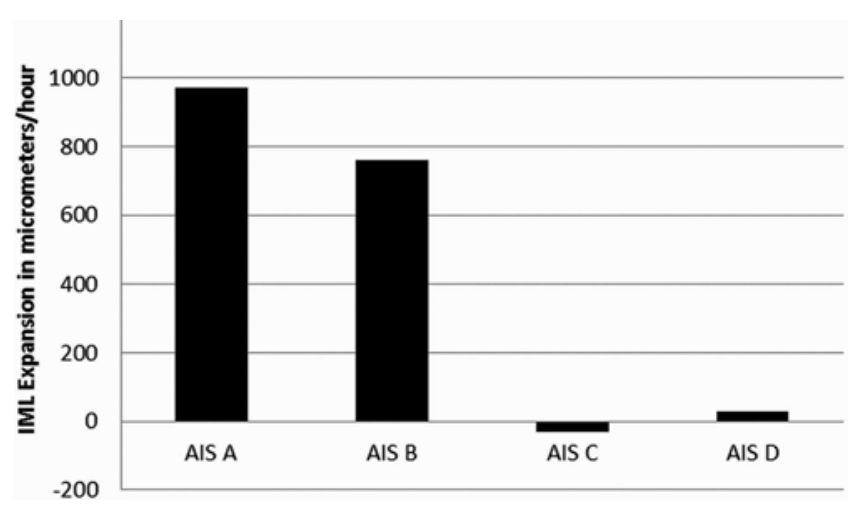

FIG. 9. Histogram illustrating the relationship between AIS grade and the IML expansion rate. 
TABLE 2. Multiple regression model indicating significance of multiple independent variables as predictors of the IML rate of expansion

\begin{tabular}{lcc}
\hline Independent Variable & Coefficient $(95 \% \mathrm{Cl})$ & p Value \\
\hline Age & $0.0056(-0.0065$ to 0.0179$)$ & 0.93 \\
\hline ISS & $-0.0022(-0.0148$ to 0.0102$)$ & 0.718 \\
\hline AMS & $-0.0002(-0.0095$ to 0.0090$)$ & 0.956 \\
\hline TPI to surgery & $0.0022(-0.0051$ to 0.0096$)$ & 0.546 \\
\hline Accidental fall & $-0.1303(-0.5231$ to 0.2625$)$ & 0.510 \\
\hline Sport injury & $0.0239(-0.3471$ to 0.3949$)$ & 0.898 \\
\hline Compression injury & $0.631(-0.3765$ to 0.5029$)$ & 0.775 \\
\hline Disc-osteophyte injury & $-0.0045(-0.4252$ to 0.4161$)$ & 0.983 \\
\hline Traction & $0.1932(-0.1572$ to 0.5436$)$ & 0.275 \\
\hline AIS Grades A \& B vs & $1.0452(0.3244$ to 1.769$)$ & $0.005^{*}$ \\
$\quad$ Grades C \& D & $-0.2618(-1.2950$ to 0.7714$)$ & 0.614 \\
\hline Constant & & \\
\hline CI = confidence interval; TPI = time past injury. \\
* Statistically significant.
\end{tabular}

SCI in terms of level of urgency for neuroprotection and timing of decompression. Many of the exigencies considered vital for the management of motor-complete SCIs, such as early initiation of therapy for neuroprotection and the timing of decompression, may not apply to motor-incomplete SCI as well as to acute traumatic central cord syndrome. ${ }^{1,58,71,73}$ In addition, the seemingly significant effects manifested by traction, the timing of decompression, and surgical technique may simply reflect increased injury severity contributing to greater spinal cord swelling and a faster IML expansion rate. . $^{32,47,77,79,80}$

There are limitations to this study. Because the study was retrospective, the allocation of Intervals 1, 2, and 3 to patients was inherently heterogeneous. Also, considering the small number of patients and their uneven distribution in each category, statistical findings should be interpreted with caution. The findings of this investigation should be validated by a prospective multicenter study.

\section{Conclusions}

The results of previous MRI studies of patients with SCI suggest that those with incomplete SCI do not harbor hematomyelia; instead, the high-intensity signal seen on MR images is indicative of swollen and interrupted axons, primarily in the dorsolateral funiculi of the involved spinal cord segments. In addition, IML length has been reported to be longer in patients with motor-complete SCI. Further expanding on these previous findings, results of the present investigation indicate that the IML in motor-complete SCI expands aggressively in association with significant swelling, whereas the IML in patients with motor-incomplete SCI is almost static with little expansion, and in some cases regression, over time. One potential implication of these findings is that the pursuit of neuroprotection should be more aggressive and earlier to interrupt the expansion of the molecular cascades forming the foundation of secondary injury.

\section{References}

1. Aarabi B, Alexander M, Mirvis SE, Shanmuganathan K, Chesler D, Maulucci C, et al: Predictors of outcome in acute traumatic central cord syndrome due to spinal stenosis. J Neurosurg Spine 14:122-130, 2011

2. Aarabi B, Simard JM, Kufera JA, Alexander M, Zacherl KM, Mirvis SE, et al: Intramedullary lesion expansion on magnetic resonance imaging in patients with motor complete cervical spinal cord injury. J Neurosurg Spine 17:243-250, 2012

3. Ackery A, Tator C, Krassioukov A: A global perspective on spinal cord injury epidemiology. J Neurotrauma 21:13551370, 2004

4. Alexander RH, Proctor HJ: Advanced Trauma Life Support (ATLS) Program for Physicians. Chicago: American College of Surgeons, 1993

5. Allen AR: Remarks on the histopathological changes in the spinal cord due to impact. An experimental study. J Nerve Ment Dis 41:141-147, 1914

6. Allen AR: Surgery of experimental lesion of spinal cord equivalent to crush injury of fracture dislocation of spinal column: a preliminary report. JAMA 57:878-880, 1911

7. Allen BL Jr, Ferguson RL, Lehmann TR, O’Brien RP: A mechanistic classification of closed, indirect fractures and dislocations of the lower cervical spine. Spine (Phila Pa 1976) $7: 1-27,1982$

8. Amar AP, Levy ML: Pathogenesis and pharmacological strategies for mitigating secondary damage in acute spinal cord injury. Neurosurgery 44:1027-1040, 1999

9. American College of Surgeons: Advanced Trauma Life Support (ATLS), ed 7. Chicago: American College of Surgeons, 2004

10. Anderberg L, Aldskogius H, Holtz A: Spinal cord injuryscientific challenges for the unknown future. Ups J Med Sci 112:259-288, 2007

11. Anderson DK: Chemical and cellular mediators in spinal cord injury. J Neurotrauma 9:143-146, 1992

12. Anthes DL, Theriault E, Tator CH: Ultrastructural evidence for arteriolar vasospasm after spinal cord trauma. Neurosurgery 39:804-814, 1996

13. Baptiste DC, Fehlings MG: Pharmacological approaches to repair the injured spinal cord. J Neurotrauma 23:318-334, 2006

14. Blood pressure management after acute spinal cord injury. Neurosurgery 50 (3 Suppl):S58-S62, 2002

15. Bracken MB, Shepard MJ, Holford TR, Leo-Summers L, Aldrich EF, Fazl M, et al: Administration of methylprednisolone for 24 or 48 hours or tirilazad mesylate for 48 hours in the treatment of acute spinal cord injury. Results of the Third National Acute Spinal Cord Injury Randomized Controlled Trial. JAMA 277:1597-1604, 1997

16. Buchanan LE, Ditunno JF Jr, Osterholm JL, Cotler JM, Staas WE Jr: Spinal cord injury: a ten-year report. Pa Med 93:3639, 1990

17. Cadotte DW, Fehlings MG: Spinal cord injury: a systematic review of current treatment options. Clin Orthop Relat Res 469:732-741, 2011

18. Carlson GD, Warden KE, Barbeau JM, Bahniuk E, KutinaNelson KL, Biro CL, et al: Viscoelastic relaxation and regional blood flow response to spinal cord compression and decompression. Spine (Phila Pa 1976) 22:1285-1291, 1997

19. Carlson SL, Parrish ME, Springer JE, Doty K, Dossett L: Acute inflammatory response in spinal cord following impact injury. Exp Neurol 151:77-88, 1998

20. Chou PC, Shunmugavel A, El Sayed H, Desouki MM, Nguyen SA, Khan M, et al: Preclinical use of longitudinal MRI for screening the efficacy of S-nitrosoglutathione in treating spinal cord injury. J Magn Reson Imaging 33:13011311,2011 
21. Chow DS, Teng Y, Toups EG, Aarabi B, Harrop JS, Shaffrey CI, et al: Pharmacology of riluzole in acute spinal cord injury. J Neurosurg Spine 17 (1 Suppl):129-140, 2012

22. Devivo MJ: Epidemiology of traumatic spinal cord injury: trends and future implications. Spinal Cord 50:365-372, 2012

23. Dohrmann GJ, Wagner FC Jr, Bucy PC: The microvasculature in transitory traumatic paraplegia. An electron microscopic study in the monkey. J Neurosurg 35:263-271, 1971

24. Dohrmann GJ, Wagner FC Jr, Bucy PC: Transitory traumatic paraplegia: electron microscopy of early alterations in myelinated nerve fibers. J Neurosurg 36:407-415, 1972

25. Dvorak MF, Fisher CG, Fehlings MG, Rampersaud YR, Oner FC, Aarabi B, et al: The surgical approach to subaxial cervical spine injuries: an evidence-based algorithm based on the SLIC classification system. Spine (Phila Pa 1976) 32:2620 2629, 2007

26. Fairholm DJ, Turnbull IM: Microangiographic study of experimental spinal cord injuries. J Neurosurg 35:277-286, 1971

27. Fehlings MG, Baptiste DC: Current status of clinical trials for acute spinal cord injury. Injury 36 (Suppl 2):B113-B122, 2005

28. Fehlings MG, Furlan JC, Massicotte EM, Arnold P, Aarabi B, Harrop J, et al: Interobserver and intraobserver reliability of maximum canal compromise and spinal cord compression for evaluation of acute traumatic cervical spinal cord injury. Spine (Phila Pa 1976) 31:1719-1725, 2006

29. Fehlings MG, Rao SC, Tator CH, Skaf G, Arnold P, Benzel E, et al: The optimal radiologic method for assessing spinal canal compromise and cord compression in patients with cervical spinal cord injury. Part II: Results of a multicenter study. Spine (Phila Pa 1976) 24:605-613, 1999

30. Fehlings MG, Vaccaro A, Wilson JR, Singh A, Cadotte WD, Harrop JS, et al: Early versus delayed decompression for traumatic cervical spinal cord injury: results of the Surgical Timing in Acute Spinal Cord Injury Study (STASCIS). PLoS ONE 7:e32037, 2012

31. Fehlings MG, Wilson JR, Frankowski RF, Toups EG, Aarabi B, Harrop JS, et al: Riluzole for the treatment of acute traumatic spinal cord injury: rationale for and design of the NACTN Phase I clinical trial. J Neurosurg Spine 17 (1 Suppl):151-156, 2012

32. Fehlings MG, Wilson JR, Karadimas SK, Arnold PM, Kopjar B: Clinical evaluation of a neuroprotective drug in patients with cervical spondylotic myelopathy undergoing surgical treatment: design and rationale for the CSM-Protect trial. Spine (Phila Pa 1976) 38 (22 Suppl 1):S68-S75, 2013

33. Feng HY, Ning GZ, Feng SQ, Yu TQ, Zhou HX: Epidemiological profile of 239 traumatic spinal cord injury cases over a period of 12 years in Tianjin, China. J Spinal Cord Med 34:388-394, 2011

34. Flanders AE, Schaefer DM, Doan HT, Mishkin MM, Gonzalez CF, Northrup BE: Acute cervical spine trauma: correlation of MR imaging findings with degree of neurologic deficit. Radiology 177:25-33, 1990

35. Fleming JC, Norenberg MD, Ramsay DA, Dekaban GA, Marcillo AE, Saenz AD, et al: The cellular inflammatory response in human spinal cords after injury. Brain 129:32493269, 2006

36. Freund P, Schmidlin E, Wannier T, Bloch J, Mir A, Schwab $\mathrm{ME}$, et al: Anti-Nogo-A antibody treatment promotes recovery of manual dexterity after unilateral cervical lesion in adult primates - re-examination and extension of behavioral data. Eur J Neurosci 29:983-996, 2009

37. Fujii H, Yone K, Sakou T: Magnetic resonance imaging study of experimental acute spinal cord injury. Spine (Phila Pa 1976) 18:2030-2034, 1993

38. Furlan JC, Fehlings MG, Massicotte EM, Aarabi B, Vaccaro
AR, Bono CM, et al: A quantitative and reproducible method to assess cord compression and canal stenosis after cervical spine trauma: a study of interrater and intrarater reliability. Spine (Phila Pa 1976) 32:2083-2091, 2007

39. Furlan JC, Kailaya-Vasan A, Aarabi B, Fehlings M: A novel approach to quantitatively assess posttraumatic cervical spinal canal compromise and spinal cord compression: a multicenter responsiveness study. Spine (Phila Pa 1976) 36:784-793, 2011

40. Furlan JC, Noonan V, Cadotte DW, Fehlings MG: Timing of decompressive surgery of spinal cord after traumatic spinal cord injury: an evidence-based examination of pre-clinical and clinical studies. J Neurotrauma 28:1371-1399, 2011

41. Guidelines for the management of acute cervical spine and spinal cord injuries. Neurosurgery 50 (3 Suppl):S1-S198, 2002

42. Guth L, Zhang Z, Steward O: The unique histopathological responses of the injured spinal cord. Implications for neuroprotective therapy. Ann N Y Acad Sci 890:366-384, 1999

43. Hovda DA, Becker DP, Katayama Y: Secondary injury and acidosis. J Neurotrauma 9 (Suppl 1):S47-S60, 1992

44. Hurlbert RJ, Hamilton MG: Methylprednisolone for acute spinal cord injury: 5-year practice reversal. Can J Neurol Sci 35:41-45, 2008

45. Iizuka H, Yamamoto H, Iwasaki Y, Yamamoto T, Konno H: Evolution of tissue damage in compressive spinal cord injury in rats. J Neurosurg 66:595-603, 1987

46. Jimenez O, Marcillo A, Levi AD: A histopathological analysis of the human cervical spinal cord in patients with acute traumatic central cord syndrome. Spinal Cord 38:532-537, 2000

47. Kalsi-Ryan S, Wilson J, Yang JM, Fehlings MG: Neurological grading in traumatic spinal cord injury. World Neurosurg 82:509-518, 2014

48. Kawata K, Morimoto T, Ohashi T, Tsujimoto S, Hoshida T, Tsunoda S, et al: [Experimental study of acute spinal cord injury: a histopathological study.] No Shinkei Geka 21:45-51, 1993 (Jpn)

49. Kurland D, Hong C, Aarabi B, Gerzanich V, Simard JM: Hemorrhagic progression of a contusion after traumatic brain injury: a review. J Neurotrauma 29:19-31, 2012

50. Kwon BK, Fisher CG, Boyd MC, Cobb J, Jebson H, Noonan $\mathrm{V}$, et al: A prospective randomized controlled trial of anterior compared with posterior stabilization for unilateral facet injuries of the cervical spine. J Neurosurg Spine 7:1-12, 2007

51. Kwon BK, Tetzlaff W, Grauer JN, Beiner J, Vaccaro AR: Pathophysiology and pharmacologic treatment of acute spinal cord injury. Spine J 4:451-464, 2004

52. Management of acute spinal cord injuries in an intensive care unit or other monitored setting. Neurosurgery 50 (3 Suppl):S51-S57, 2002

53. Martin D, Schoenen J, Lenelle J, Reznik M, Moonen G: MRI-pathological correlations in acute traumatic central cord syndrome: case report. Neuroradiology 34:262-266, 1992

54. Miyanji F, Furlan JC, Aarabi B, Arnold PM, Fehlings MG: Acute cervical traumatic spinal cord injury: MR imaging findings correlated with neurologic outcome-prospective study with 100 consecutive patients. Radiology 243:820827,2007

55. National Spinal Cord Injury Statistical Center: Spinal cord injury facts and figures at a glance. J Spinal Cord Med 37:117-118, 2014

56. Nishi RA, Liu H, Chu Y, Hamamura M, Su MY, Nalcioglu $\mathrm{O}$, et al: Behavioral, histological, and ex vivo magnetic resonance imaging assessment of graded contusion spinal cord injury in mice. J Neurotrauma 24:674-689, 2007

57. Nout YS, Mihai G, Tovar CA, Schmalbrock P, Bresnahan JC, Beattie MS: Hypertonic saline attenuates cord swelling and edema in experimental spinal cord injury: a study utilizing 
magnetic resonance imaging. Crit Care Med 37:2160-2166, 2009

58. Papadopoulos SM, Selden NR, Quint DJ, Patel N, Gillespie $\mathrm{B}$, Grube S: Immediate spinal cord decompression for cervical spinal cord injury: feasibility and outcome. J Trauma 52:323-332, 2002

59. Quencer RM, Bunge RP, Egnor M, Green BA, Puckett W, Naidich TP, et al: Acute traumatic central cord syndrome: MRI-pathological correlations. Neuroradiology 34:85-94, 1992

60. Schaefer DM, Flanders A, Northrup BE, Doan HT, Osterholm JL: Magnetic resonance imaging of acute cervical spine trauma. Correlation with severity of neurologic injury. Spine (Phila Pa 1976) 14:1090-1095, 1989

61. Schaefer DM, Flanders AE, Osterholm JL, Northrup BE: Prognostic significance of magnetic resonance imaging in the acute phase of cervical spine injury. J Neurosurg 76:218223, 1992

62. Senter HJ, Venes JL: Loss of autoregulation and posttraumatic ischemia following experimental spinal cord trauma. J Neurosurg 50:198-206, 1979

63. Short D: Is the role of steroids in acute spinal cord injury now resolved? Curr Opin Neurol 14:759-763, 2001

64. Simard JM, Popovich PG, Tsymbalyuk O, Caridi J, Gullapalli RP, Kilbourne MJ, et al: MRI evidence that glibenclamide reduces acute lesion expansion in a rat model of spinal cord injury. Spinal Cord 51:823-827, 2013

65. Simard JM, Popovich PG, Tsymbalyuk O, Gerzanich V: Spinal cord injury with unilateral versus bilateral primary hemorrhage-effects of glibenclamide. Exp Neurol 233:829-835, 2012

66. Simard JM, Woo SK, Norenberg MD, Tosun C, Chen Z, Ivanova S, et al: Brief suppression of Abcc8 prevents autodestruction of spinal cord after trauma. Sci Transl Med 2:28ra29, 2010

67. Tator $\mathrm{CH}$ : Review of experimental spinal cord injury with emphasis on the local and systemic circulatory effects. Neurochirurgie 37:291-302, 1991

68. Tator CH, Fehlings MG: Review of the secondary injury theory of acute spinal cord trauma with emphasis on vascular mechanisms. J Neurosurg 75:15-26, 1991

69. Turnbull IM: Chapter 5. Blood supply of the spinal cord: normal and pathological considerations. Clin Neurosurg 20:56-84, 1973

70. Turnbull IM: Microvasculature of the human spinal cord. J Neurosurg 35:141-147, 1971

71. Vaccaro AR, Daugherty RJ, Sheehan TP, Dante SJ, Cotler JM, Balderston RA, et al: Neurologic outcome of early versus late surgery for cervical spinal cord injury. Spine (Phila Pa 1976) 22:2609-2613, 1997

72. Vaccaro AR, Hulbert RJ, Patel AA, Fisher C, Dvorak M, Lehman RA Jr, et al: The subaxial cervical spine injury classification system: a novel approach to recognize the importance of morphology, neurology, and integrity of the disco-ligamentous complex. Spine (Phila Pa 1976) 32:2365-2374, 2007

73. Vale FL, Burns J, Jackson AB, Hadley MN: Combined medical and surgical treatment after acute spinal cord injury: results of a prospective pilot study to assess the merits of aggressive medical resuscitation and blood pressure management. J Neurosurg 87:239-246, 1997

74. van Middendorp JJ, Hosman AJ, Doi SA: The effects of the timing of spinal surgery after traumatic spinal cord injury: a systematic review and meta-analysis. J Neurotrauma 30:1781-1794, 2013

75. Wagner FC Jr, Dohrmann GJ, Bucy PC: Histopathology of transitory traumatic paraplegia in the monkey. $\mathbf{J}$ Neurosurg 35:272-276, 1971

76. Waring WP III, Biering-Sorensen F, Burns S, Donovan W, Graves D, Jha A, et al: 2009 review and revisions of the International Standards for the Neurological Classification of Spinal Cord Injury. J Spinal Cord Med 33:346-352, 2010

77. Wilson JR, Arnold PM, Singh A, Kalsi-Ryan S, Fehlings MG: Clinical prediction model for acute inpatient complications after traumatic cervical spinal cord injury: a subanalysis from the Surgical Timing in Acute Spinal Cord Injury Study. J Neurosurg Spine 17 (1 Suppl):46-51, 2012

78. Wilson JR, Fehlings MG: Riluzole for acute traumatic spinal cord injury: a promising neuroprotective treatment strategy. World Neurosurg 81:825-829, 2014

79. Wilson JR, Grossman RG, Frankowski RF, Kiss A, Davis AM, Kulkarni AV, et al: A clinical prediction model for longterm functional outcome after traumatic spinal cord injury based on acute clinical and imaging factors. J Neurotrauma 29:2263-2271, 2012

80. Wilson JR, Singh A, Craven C, Verrier MC, Drew B, Ahn $\mathrm{H}$, et al: Early versus late surgery for traumatic spinal cord injury: the results of a prospective Canadian cohort study. Spinal Cord 50:840-843, 2012

81. Wu Y, Satkunendrarajah K, Teng Y, Chow DS, Buttigieg J, Fehlings MG: Delayed post-injury administration of riluzole is neuroprotective in a preclinical rodent model of cervical spinal cord injury. J Neurotrauma 30:441-452, 2013

82. Yang R, Guo L, Wang P, Huang L, Tang Y, Wang W, et al: Epidemiology of spinal cord injuries and risk factors for complete injuries in Guangdong, China: a retrospective study. PLOS ONE 9:e84733, 2014

\section{Author Contributions}

Conception and design: Aarabi. Acquisition of data: Aarabi, Le, Hersh, Shanmuganathan, Diaz, Massetti. Analysis and interpretation of data: Aarabi, Akhtar-Danesh. Drafting the article: Aarabi, Le. Critically revising the article: Aarabi, Le, AkhtarDanesh. Reviewed submitted version of manuscript: all authors. Approved the final version of the manuscript on behalf of all authors: Aarabi. Statistical analysis: Aarabi, Akhtar-Danesh. Administrative/technical/material support: Aarabi. Study supervision: Aarabi. Oversight for the scientific foundation and data safety and monitoring: Aarabi.

\section{Correspondence}

Bizhan Aarabi, Department of Neurosurgery, University of Maryland School of Medicine, 22 S. Greene St., Ste. S-12-D, Baltimore, MD 21201. email: baarabi@smail.umaryland.edu. 